\title{
WATERFALL MODELLING PADA SISTEM E-RESTORANT
}

\author{
Agung Triayudi ${ }^{1}$ Achmad Syaifudin Rodhi ${ }^{2}$ \\ ${ }^{1}$ Fakultas Teknologi Komunikasi dan Informatika, Universitas Nasional \\ ${ }^{2}$ Informatika, Fakultas Teknologi Informasi, Universitas Serang Raya \\ ${ }^{1}$ agungtriayudiecivitas.unas.ac.id \\ ${ }^{2}$ syaifudinrodhi@gmail.com
}

\begin{abstract}
Abstrak-Aplikasi layanan pesan antar merupakan sistem informasi berbasis Android yang yang bertujuan untuk mempermudah dan mengoptimalkan layanan pesan antar makanan pada restoran Krebo Jantan. Aplikasi layanan pesan antar ini dirancang menggunakan model UML (Unified Modelling Language) dibangun menggunakan bahasa pemograman Java serta MySQL sebagai databasenya. Dalam pengembangan sistem menggunakan metode Waterfall, pengujian sistemnya menggunakan black box dan penilaian sistem menggunakan skala likert. Hasil penelitian menyimpulkan bahwa Aplikasi Layanan Pesan Antar Makanan Pada Restoran Krebo Jantan Berbasis Android ini, diharapkan dapat bermanfaat bagi Restoran Krebo Jantan dalam mengoptimalkan layanan pesan antar makanan dan untuk pelanggan dapat lebih mudah melakukan proses pemesanan serta dapat menghemat biaya.
\end{abstract}

Kata Kunci: Aplikasi Layanan Pesan Antar, Restoran, Android, MySQL, Waterfall, Black box, Skala likert

\section{PENDAHULUAN}

\subsection{Latar Belakang}

Perkembangan teknologi yang sangat cepat telah membawa manusia memasuki kehidupan yang berdampingan dengan informasi dan teknologi. Dengan teknologi informasi yang berkembang saat ini (Triayudi, 2014). pengelolaan informasi dapat dilakukan secara lebih aktual dan optimal. Penggunaan teknologi informasi bertujuan untuk mencapai efisiensi dalam berbagai aspek pengelolaan informasi, yang ditunjukkan untuk kecepatan dan ketepatan waktu pemrosesan, serta ketelitian dan keakuratan informasi (Triayudi, 2017).

Saat ini banyak bisnis kuliner yang semakin bersaing, disamping menu yang disajikan, layanan restoran juga sangat berpengaruh yaitu dalam memberikan kepuasan kepada pelanggan. Dengan adanya alternatif layanan pesan antar pada restoran akan memudahkan pelanggan dalam memesan makanan tanpa datang ke restoran. Melihat banyaknya bisnis kuliner di dunia nyata yang menerapkan layanan pesan antar restoran secara manual mempunyai dampak kinerja yang kurang efisien dan efektif. Sehingga dalam segi waktu dan pengelolaan restoran bergantung pada kinerja setiap pegawai restoran.

Dalam ilmu bisnis, Delivery Order atau Layanan Pesan Antar merupakan salah satu aktivitas dan pemberian jasa dimana pelanggan memesan produk yang disediakan produsen dan biasanya menggunakan media komunikasi melalui telepon atau internet lalu produk yang dipesan akan diantarkan sampai ke tempat pelanggan berada tanpa perlu datang dan bertemu langsung dengan penjualan atau produsen. Aktivitas ini dilakukan sebagai penunjang citra bisnis dengan memberikan pelayanan yang terbaik bagi pelanggan (Khusnul, 2015).

Krebo Jantan adalah sebuah restoran yang sedang berkembang, terletak di Jalan Bukti Baja Sejahtera Ciwaduk Kec. Cilegon Kota Cilegon Banten 42415. Restoran ini menawarkan berbagai menu yang terbagi dalam 5 katagori, yaitu makanan, pisang, snack, minuman, dan es krim. Konsep yang ditawarkan Krebo Jantan adalah tempat makan yang nyaman dan terkini. Sebelumnya Krebo Jantan sudah memiliki sistem pesan antar secara manual yaitu dengan menggunakan telepon. Tingginya tarif pulsa telepon dengan area layanan terbatas ikut mendorong pelanggan malas memanfaatkan jasa ini. Penggunaannya pun belum maksimal, pelanggan tidak bisa mengetahui daftar menu makanan dan minuman serta sering terjadi kesalahpahaman antara pelanggan dan pihak restoran terkait informasi ciriciri menu yang disampaikan melalui telepon. Sistem seperti ini sudah tidak layak lagi untuk digunakan 
disaat waktu menjadi hal yang sangat penting karena aktivitas manusia yang terus meningkat.

Aplikasi layanan pesan antar makanan merupakan sistem informasi berbasis Android yang menyediakan proses pemesanan menu makanan restoran yang bertujuan untuk mempermudah dan mengoptimalkan layanan pesan antar makanan pada restoran. Pelanggan yang ingin memesan menu makanan dapat mengakses sistem ini menggunakan smartphone berbasis Android. Menu makanan yang dilengkapi dengan tampilan gambar dan daftar harga yang sesuai dengan jenis makanan yang tersedia. Proses pengiriman makanan dilakukan secara manual oleh kurir yang bertugas. Dengan demikian pelanggan yang menggunakan sistem ini dapat lebih mudah melakukan proses pemesanan serta dapat menghemat biaya.

Dari uraian tersebut akan dibangun sebuah aplikasi "APLIKASI LAYANAN PESAN ANTAR MAKANAN PADA RESTORAN KREBO JANTAN BERBASIS ANDROID”. Yang tujuannya aplikasi ini dapat memudahkan pelanggan dalam melakukan proses pemesanan serta dapat membantu dan memajukan restoran dalam hal meningkatkan pelayanan delivery yang dapat diakses oleh pelanggan dan memudahkan pemilik restoran dalam mengelola restoran.

\subsection{Rumusan Masalah}

Berdasarkan latar belakang yang telah dijelaskan di atas maka rumusan masalah dari penelitian yang dilakukan adalah sebagai berikut:

1. Bagaimana membuat aplikasi layanan pesan antar makanan pada restoran Krebo Jantan berbasis android yang memudahkan pemesanan menu makanan bagi pelanggan?

2. Bagaimana membuat aplikasi berbasis Android yang menyediakan informasi yang lengkap tentang menu makanan yang terdapat pada restoran Krebo Jantan?

3. Bagaimana aplikasi ini dapat membantu pihak restoran Krebo Jantan dalam mengelola layanan pesan antar agar lebih efisien dan efektif?

\subsection{Tujuan Penelitian}

Penulis penelitian ini memiliki beberapa tujuan yaitu:

1. Penelitian ini bertujuan untuk membuat aplikasi pesan antar makanan pada restoran Krebo Jantan berbasis android untuk memudahkan pemesanan menu makanan bagi pelanggan.

2. Meningkatkan kinerja pada restoran Krebo Jantan dalam hal pelayanan pelanggan.

\section{LANDASAN TEORI}

\subsection{Android OS}

Android merupakan OS (Operating System) mobile yang tumbuh di tengah OS lainnya yang berkembang dewasa ini. OS lainnya seperti Windows Mobile, i-Phone, Symbian. Akan tetapi OS yang ada ini berjalan dengan memprioritaskan aplikasi inti yang dibangun sendiri tanpa melihat potensi yang cukup besar dari aplikasi pihak ketiga (Hermawan, 2011).

\subsection{Android Studio}

Android Studio adalah Lingkungan Pengembangan Terpadu - Integrated Development Environment (IDE) untuk pengembangan aplikasi Android. Selain merupakan editor kode IntelliJ dan alat pengembang yang berdaya guna, Android Studio menawarkan fitur lebih banyak untuk meningkatkan produktivitas Anda saat membuat aplikasi Android.

\subsection{Java}

Java adalah bahasa pemrograman yang dapat dijalankan diberbagai computer termasuk telepon genggam. Bahasa ini awalnya dibuat oleh James Gosling saat masih bergabung di Sun Microsystems saat ini merupakan bagian dari Oracle dan dirilis tahun 1995. Java merupakan bahasa pemrograman yang bersifat umum/non-spesifik (general purpose), dan secara khusus dibuat untuk memanfaatkan dependensi implementasi seminimal mungkin. Karena fungsionalitasnya yang memungkinkan aplikasi java mampu berjalan di beberapa platform sistem operasi yang berbeda. Saat ini java merupakan bahasa pemrograman yang paling popular digunakan, dan secara luas dimanfaatkan dalam pengembangan berbagai jenis perangkat lunak aplikasi ataupun aplikasi.

\subsection{MySQL}

Pengertian MYSQL Menurut Nugroho (2009:1), MySQL adalah sebuah program database server yang mampu menerima dan mengirimkan datanya dengan sangat cepat, multi user, serta menggunakan perinta standar SQL. MYSQL merupakan Free Software dibawah lisensi GNU/GPL (General Public License).

\subsection{Delivery Order}

Dalam ilmu bisnis, Delivery Order atau Layanan Pesan Antar merupakan salah satu aktivitas dan pemberian jasa dimana pelanggan memesan produk yang disediakan produsen dan biasanya menggunakan media komunikasi melalui telepon atau internet lalu produk yang dipesan akan diantarkan sampai ke tempat pelanggan berada tanpa perlu datang dan bertemu langsung dengan penjualan atau produsen. Aktivitas ini dilakukan 
sebagai penunjang citra bisnis dengan memberikan pelayanan yang terbaik bagi pelanggan (Khusnul, 2015).

\subsection{Unified Modeling Language(UML)} Menurut Nugroho (2010:6), "UML (Unified Modeling Language) adalah 'bahasa' pemodelan untuk sistem atau perangkat lunak yang berparadigma 'berorientasi objek". Pemodelan (modeling) sesungguhnya digunakan untuk penyederhanaan permasalahan-permasalahan yang kompleks sedemikian rupa sehingga lebih mudah dipelajari dan dipahami".

Menurut Nugroho (2009:4), "UML (Unified Modeling Language) adalah Metodologi kolaborasi antara metoda-metoda Booch,OMT (Object Modeling Technique), serta OOSE (object Oriented Software Enggineering) dan beberapa metoda lainnya, merupakan metodologi yang paling sering digunakan saat ini untuk analisa dan perancangan sistem dengan metodologi berorientasi objek mengadaptasi maraknya penggunaan bahasa pemrograman berorientasi objek (OOP)".

\subsection{Metodelogi Penelitian}

Penelitian ini memiliki tujuan mempermudah dan mengoptimalkan layanan pesan antar makanan pada restoran Krebo Jantan. Pelanggan yang ingin memesan menu makanan dapat mengakses sistem ini menggunakan smartphone berbasis Android. Menu makanan yang dilengkapi dengan tampilan gambar dan daftar harga yang sesuai dengan jenis makanan yang tersedia. Proses pengiriman makanan dilakukan secara manual oleh kurir yang bertugas. Dengan demikian pelanggan yang menggunakan sistem ini dapat lebih mudah melakukan proses pemesanan serta dapat menghemat biaya dan waktu, dimana saat ini waktu menjadi hal yang sangat penting karena aktivitas manusia yang terus mengingkat.

Pengembangan sistem yang digunakan pada penelitian ini adalah dengan menggunakan model Waterfall. Metode air terjun atau yang sering disebut metode waterfall sering dinamakan siklus hidup klasik (classic life cycle), dimana hal ini menggambarkan pendekatan yang sistematis dan juga berurutan pada pengembangan perangkat lunak, dimulai dengan spesifikasi kebutuhan pengguna lalu berlanjut melalui tahapan-tahapan perencanaan (planning), permodelan (modeling), konstruksi (construction), serta penyerahan sistem ke para pelanggan/pengguna (deployment), yang diakhiri dengan dukungan pada perangkat lunak lengkap yang dihasilkan (Pressman, 2012).
Tahapan medote waterfall :

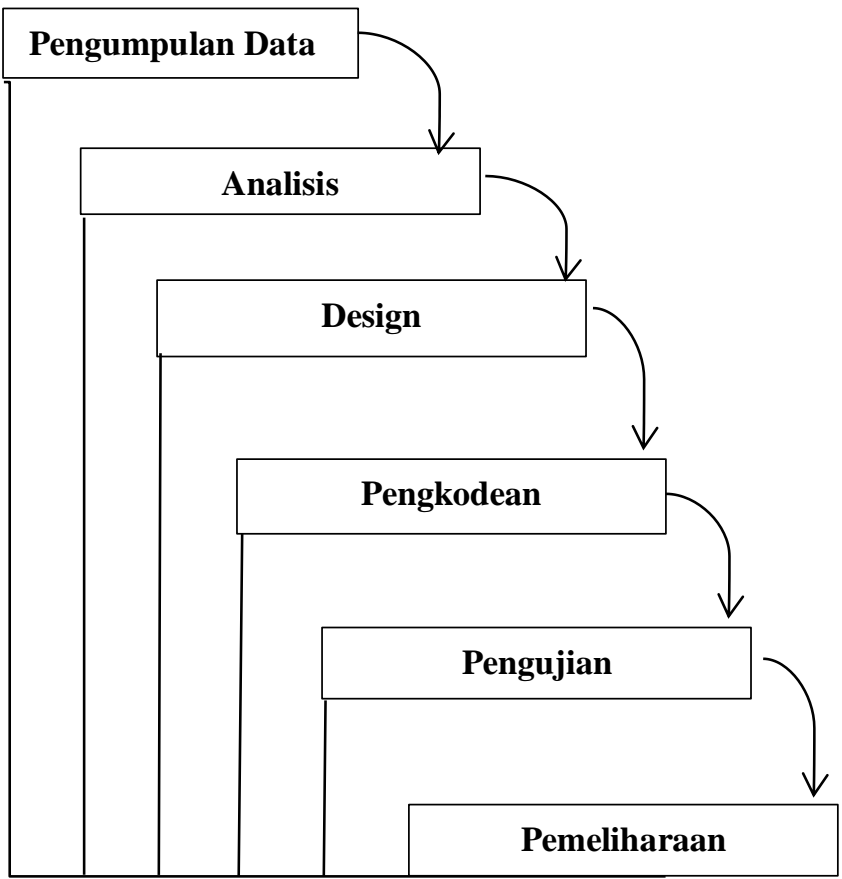

Gambar 1. Model Waterfall

1. Pengumpulan data

Pengumpulan data merupakan usaha yang dilakukan untuk memperoleh informasi dalam bentuk data yang dibutuhkan dalam penelitian. Data yang paling dibutuhkan pada pembuatan aplikasi ini adalah data menu makanan dan data meja yang terdapat pada Restorant Krebo Jantan. Data dapat diperoleh melalui wawancara, observasi dan study pustaka. Data tersebut kemudian dianalisis untuk mendapatkan dokumentasi kebutuhan pengguna untuk digunakan pada tahap selanjutnya.

2. Analisis

Tahap berikutnya setelah data terkumpul adalah tahap analisis kebutuhan sistem. Kegiatan ini diintensifkan dan difokuskan pada sistem, yaitu menganalisa kebutuhan dan persyaratan proses pada sistem yang akan dibangun.

3. Design

Tahap ini dilakukan sebelum melakukan coding. bertujuan untuk memberikan gambaran apa yang seharusnya dikerjakan dan bagaimana tampilannya. Pada proses ini melibatkan struktur data, arsitektur, perangkat lunak, representasi interface dan detail (algoritma) prosedural. Desain yang penulis lakukan adalah berbasis web, agar sistem yang penulis buat dapat diakses dimana saja oleh masyarakat. 
4. Pengkodean

Tahapan implementasi merupakan tahapan mengubah rancangan yang telah dibuat menjadi kumpulan kode atau instruksi yang akan dijalankan oleh komputer.Bahasa Pemrograman yang digunakan oleh penulis adalah Java.

5. Pengujian

Penggabungan modul-modul yang sudah dibuat pada tahap sebelumnya dan dilakukan pengujian untuk mengetahui sistem yang dibuat telah sesuai desainnya dan masih terdapat kesalahan atau tidak.

6. Pemeliharaan

Pada tahap terakhir perangkat lunak yang sudah dijalankan harus dilakukan pemeliharaan. Pemeliharaan ini termasuk dalam perbaikan kesalahan pada perangkat lunak yang tidak ditemukan pada tahap sebelumnya.

\section{HASIL DAN PEMBAHASAN}

Dalam pembahasan ini dideskripsikan secara detail tampilan yang terdapat pada Aplikasi Layanan Pesan Antar Makanan Pada Restoran Krebo Jantan Berbasis Android yang dibuat guna membantu jalannya aplikasi beserta dilengkapi dengan fitur dan fungsinya masing-masing:

a. Halaman Utama User merupakan halaman utama setelah user berhasil login.

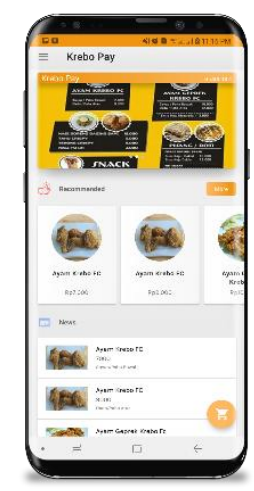

\section{Gambar 2. Halaman Utama User}

b. Halaman Menu Aplikasi merupakan menu-menu yang terdia di aplikasi layanan pesan antar makanan berbasis Android ini.

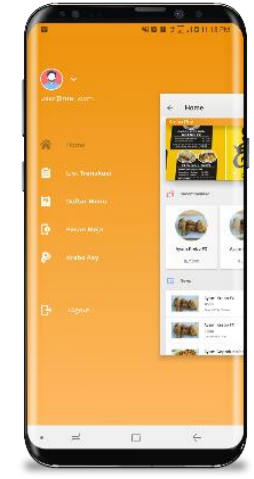

\section{Gambar 3. Halaman Menu Aplikasi}

c. Halaman Pesan Menu merupakan halaman dimana user untuk memesan makanan. Dalam halaman ini terdapat semua menu makanan yang tersedia di Restoran Krebo Jantan.

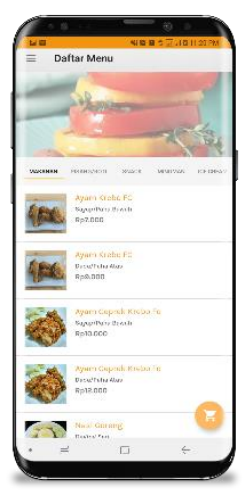

\section{Gambar 4. Halaman Pesan Menu}

d. Halaman Detail Menu merupakan halaman dimana user untuk memesan makanan. Dalam halaman ini terdapat detail menu makanan yang telah dipilih oleh user.

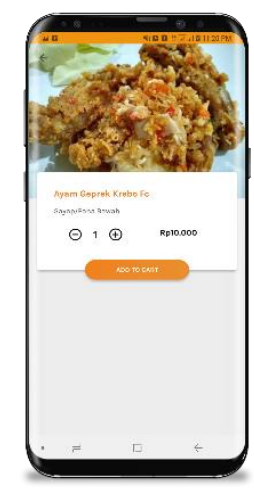

\section{Gambar 5. Halaman Detail Menu}

e. Halaman konfirmasi pesanan merupakan halaman konfirmasi data pesanan dan data user sebelum pesanan tersebut dikirim ke Admin. Dalam halaman ini terdapat maps yang digunakan untuk menentukan alamat yang dituju untuk pengiriman pesanan. 


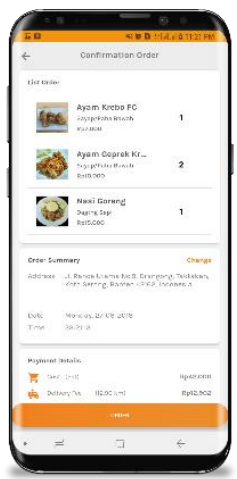

\section{Gambar 6. Halaman Konfirmasi}

f. Halaman pesan meja merupakan halaman dimana user dapat memesan meja sesuai dengan jam yang diinginkan.

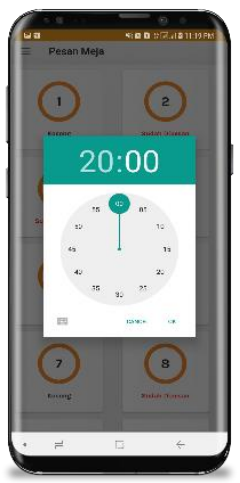

\section{Gambar 7. Halaman Pesan Meja}

\subsection{Pembahasan Android}

Setelah mengidentifikasi komponen-komponen yang dibutuhkan dalam pembuatan aplikasi layanan pesan antar makanan berbasis Android maka peneliti menggabungkan beberapa software yang digunakan dalam pembuatan aplikasi layanan pesan antar tersebut, yaitu: Android Studio dan Notepad++.

\subsection{Pengujian}

Pengujian sistem merupakan elemen kritis dari Software Quality Assurance (SQA) dan mempresentasikan review akhir dari spesifikasi kebutuhan aplikasi, perancangan dan implementasi. Tujuan utama dari pengujian sistem adalah untuk memastian bahwa hubungan antar modul aplikasi telah memenuhi spesifikasi kebutuhan dan berjalan sesuai dengan skenario yang telah dideskripsikan. Setelan sistem selesai dibuat, selanjutnya sistem akan coba dijalankan dengan menguji apakah sistem tersebut sudah layak digunakan atau belum. Pada tahap ini pengujian dilakukan oleh pihak Restoran Krebo Jantan dan beberapa pelanggan Restoran Krebo Jantan dengan metode pengujian blackbox.

\subsection{Pemeliharaan}

Tahap ini merupakan tahap terakhir dalam metode waterfall, sistem yang sudah dilakukan untuk diuji kebenarannya, serta dilakukan pemeliharaan yang mencakup koreksi dari berbagai kesalahan yang tidak ditemukan pada tahap-tahap sebelumnya, perbaikan atas implementasi dan pengembangan sistem, serta pemeliharaan program. Pemeliharaan sistem dapat dilakukan oleh seorang administrator untuk meningkatkan kualitas sistem agar jauh lebih baik. Dalam pelaksanaan pemeliharaan sistem dilakukan secara berkala yaitu setiap minggu.

Ada 3 alasan perlunya pemeliharaan sistem, yaitu :

a. Untuk membenarkan kesalahan atau kelemahan sistem yang tidak terdeteksi pada saat pengujian.

b. Untuk membuat sistem up to date.

c. Untuk meningkatkan kemampuan sistem.

\section{KESIMPULAN}

Berdasarkan uraian pada bab-bab sebelumnya, maka dapat ditarik kesimpulan bahwa:

1. Dengan adanya Aplikasi Layanan Pesan Antar Makanan berbasis Android ini dapat mempermudah pelanggan restoran Krebo Jantan dalam memesan makanan tanpa harus datang langsung ke restoran.

2. Dalam Aplikasi Layanan Pesan Antar Makanan berbasis Android ini terdapat informasi yang lengkap mengenai menu makanan yang terdapat pada restoran Krebo Jantan.

3. Dengan penerapan Aplikasi Layanan Pesan Antar Makanan berbasis Android dapat mengoptimalkan pihak restoran Krebo Jantan dalam mengelola layanan pesan antar agar lebih efisien dan efektif.

\section{PUSTAKA}

Busran dan Wina Anggraini. 2016. Perancangan Aplikasi Pemesanan Makanan Dan Minuman Berbasis Sistem Operasi Android. Padang : Jurnal Teknoif, Vol.4 No. 1 April 2016.

Caniati, Nia dkk. 2017. Implementasi Sistem Informasi Pemesanan Menu Makanan Dan Minuman Pada Kafe Berbasis Web Menggunakan Jaringan Intranet. Indramayu : Jurnal Ilmiah Ilmu Komputer, Vol.3, No.2, September 2017.

Inayah, Immah dkk. 2015. Aplikasi Pemesanan Makanan Berbasis Web (Studi Kasus RM Lesehan Berkah Ilaahi Gresik). Surabaya: ejurnal NARODROID, vol. 1, No. 2 Juli 2015.

Khusnul. 2015. Merancang Bisnis Jasa Layanan Pesan Antar [Online]. Tersedia: http://www.trainingusaha.com/merancang- 
bisnis-jasa-layanan-pesan-antar/. Diakses pada tanggal 19 April 2018.

Kusuma, Abdi Pandu dan Kurniawan Agus Prasetya. 2017. Perancangan Dan Implementasi E-Commerce Untuk Penjualan Baju Online Berbasis Android. Blitar : Jurnal Antivirus, Vol. 11 No. 1 Mei 2017.

Samudra, Zaldy. 2015. Aplikasi Delivery Makanan Berbasis Web Di Area Telkom University. Bandung : e-proceeding of Applied Science : Vol.1 No. 1 April 2015.

Triayudi, A., Rosalina, V. and Fildzah, F., 2014.
RANCANG
BANGUN
SISTEM
PENGOLAHAN SUPPLIER INVOICE
ACCOUNTING MENGGUNAKAN
METODE
EXTREME
PROGRAMMING. PROSISKO: Jurnal Pengembangan Riset dan Observasi Sistem Komputer, 1 .

Triayudi, A., 2017. Mengukur Tingkat Pembiayaan Kredit Pada PT. Trihamas Finance Menggunakan Algoritma Apriori-Data Mining. ProTekInfo (Pengembangan Riset dan Observasi Teknik Informatika), 4, pp.15.

Wikipedia. 2016. Android OS. [Online]. Tersedia: https://id.wikipedia.org/wiki/Android (sistem_operasi). Diakses pada tanggal 18 April 2018. 